\title{
Impact of health education on rural adolescent girls of Haryana
}

\author{
SAVITA SANGWAN, VINTI DAVAR AND SHRESHTHA MURAAL
}

Received: 24.04.2014; Revised: 26.09.2014; Accepted: 09.10.2014

See end of the paper for authors' affiliations

\section{VINTI DAVAR}

Department of Home Science, Kurukshetra University, KURUKSHETRA (HARYANA) INDIA Email: vintidavar@gmail.com
ABSTRACT : Adolescence is a period of rapid physical and biological changes and prime time for health promotion and to encourage adolescents to establish healthy patterns of behaviour that will influence their development and health in later years. In this context a health education programme was structured and charts, posters and other education material were prepared. A pre-test post-test experimental design was employed and the study was a cross-sectional study. From two stratified areas of Rohtak and Bhiwani districts of Haryana, a total sample of 300 adolescent girls in the age group of 13-19 years were selected by random sampling from two villages each Kanni and Shangi and Mehraa and Badeshra from each district, respectively. Assessment was done by self-structured knowledge inventory. Knowledge towards health education was divided into seven major sub-aspects i.e. personal hygiene, nutrition and health, family planning, maternal and child care, HIV/ AIDS and physical and emotional health. Pre and post testing performances of experimental and control group respondents were compared using t- test. The messages through prepared charts, posters, leaflets and pamphlets were found most appropriate according to the title/slogan, clarity of picture, colour combination, attractiveness, usefulness, selfexplanation, relevance of graphic/text of the topic and general get up. A significant positive impact $(\mathrm{P}<0.01)$ of educational programme on the knowledge of experimental group respondents was observed. Improvement has been noted in the respondents from low and moderate categories to high level at post testing stage of imparting health education.

KEY WORDS: Adolescents, Health education, Rural girls

HOW TO CITE THIS PAPER : Sangwan, Savita, Davar, Vinti and Muraal, Shreshtha (2014). Impact of health education on rural adolescent girls of Haryana. Asian J. Home Sci., 9 (2) : 431-435. 